\title{
Nutritional management in children with disease-related malnutrition : what's the guideline?
}

\author{
I Gusti Lanang Sidiartha ${ }^{1}$ \\ 1. Nutrition and metabolic diseases division, pediatric department, faculty of medicine. \\ Universitas Udayana, Sanglah general hospital
}

Received 21 October 2021 Accepted 21 February 2022 Published: 28 February 2022

Link to DOI: $\underline{\text { 10.25220/WNJ.V05.i2.0006 }}$

Citation: Sidiartha IGL. Nutritional management in children with disease-related malnutrition: what's the guideline?. World Nutrition Journal.2022 Feb 28, 5(2):32-41.

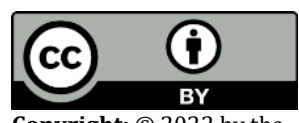

Copyright: (C) 2022 by the authors. This article is an open access article distributed under the terms and conditions of the Creative Commons Attribution (CC BY) license (https:// creativecommons.org/licenses/b y/ 4.0/).

Website :

http://www.worldnutrijournal.o rg/

\begin{abstract}
Background: Disease-related malnutrition (DRM) is one of the most common problems in pediatric patients. Both cancer and congenital heart diseases (CHD) are commonly associated with DRM. Altered nutrition utilization, reduced intake, malabsorption, and hypermetabolism are the main pathophysiology in DRM.

Method: A systematic literature searching was performed through Pubmed and Google Scholar websites. Thirty-six articles were included into the study.

Results: Malnutrition screening should be performed as soon as possible since early feeding can benefit the patients. One of the most commonly used tools is Screening Tool for Risk on Nutritional

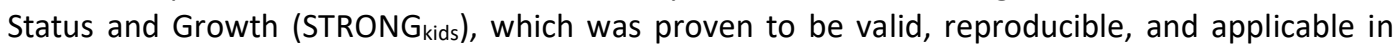
pediatric patients with malnutrition. Following screening and assessment, nutrition support can ensue, preferably in the form of enteral nutrition, unless contraindicated. Nutrient-dense formula, also known as protein and energy-enriched formula, aims to aid infants to reach nutrition target rapidly and stimulate anabolism. This formula has been studied in various population, mostly infants with CHD and studies showed favorable outcomes with its administration, namely faster improvement, reduced diuretics use and oxygen supplementation, decreased length of hospital stay, and less antibiotic use. Nutrient-dense formula is also safe and well-tolerated.

Conclusion: Proper screening and management should be performed with multidisciplinary approach to achieve the best outcome in children with DRM.

Keywords: nutritional management, disease-related malnutrition. cancer, congenital heart disease, nutrientdense formula
\end{abstract}

\section{Introduction}

Malnutrition, one of the most common problems encountered in pediatric patients, is defined as a condition of excess or lack of protein, energy, or other nutrients which affects the function and structure of the body. ${ }^{1}$ Hence, malnutrition implies obesity and undernutrition. Double burden malnutrition $(\mathrm{DBM})$ is a concerning problem

\footnotetext{
Corresponding author:

I Gusti Lanang Sidiartha

Faculty of Medicine, Universitas Udayana, Sanglah

General Hospital

Email : lanangsidiartha@yahoo.com
}

worldwide where obesity and undernutrition occur together. $^{2}$ Approximately 165 million children experience undernutrition worldwide with $90 \%$ of the cases are from Asia and Africa. ${ }^{3}$ Indonesia, a middle-income country, is affected by this DBM as well. About $37 \%$ of the children aged under 5 years old in Indonesia experience stunting and $12 \%$ of the same population experience wasting. ${ }^{2}$ On the other hand, approximately $11,5 \%$ of children aged 6-12 years old in Indonesia experience obesity. ${ }^{4}$

Based on the chronicity, malnutrition is classified into acute malnutrition for duration less than 3 months and chronic malnutrition for duration of 3 
months or longer. Acute malnutrition is often associated with burns, infectious diseases, and trauma as chronic malnutrition is associated with chronic diseases, such as chronic pulmonary disorders, malignancies, and cystic fibrosis. As for etiologic classification, malnutrition is classified into disease-related malnutrition (DRM) and not DRM, which relates to environmental, behavioral, and socioeconomical factors. ${ }^{5}$

Disease-related malnutrition is identified in 6$51 \%$ of hospitalized pediatric patients. However, this is often underdiagnosed..$^{5} \mathrm{DRM}$ is mostly associated with infectious disease, gastrointestinal disorders, endocrine disorders, metabolic disorders, as well as neuropsychiatric disorders. This condition might predispose the pediatric patients to poor outcomes, such as disrupted wound healing process, higher infection rates, longer length of stay (LOS), poor quality of life, and higher risk of surgical and medical complications. As for the stakeholders, this can lead to increased costs which affects the country's economic status. ${ }^{6}$

As this DRM can increase the pediatric patients' morbidity and mortality rates, a proper screening and management algorithm is necessary. Multidisciplinary approach should be implemented to achieve an optimal outcome. ${ }^{7}$ Therefore, this review aims to discuss the guidelines for nutritional management in children with DRM.

\section{Methods}

Search of literatures were performed through Pubmed and Google Scholar websites using keywords "Disease-related Malnutrition", "Children", "Congenital Heart Disease", "Cancer", and "Nutrient-dense formula". A total of 530 articles were found. After screening, 35 articles were included. Most articles were review articles and four articles were randomized controlled trials. The articles were published between 2010 and 2021. Article selection process is shown in Figure 1.

\section{Result}

Disease-related malnutrition in children with congenital heart diseases
The prevalence of congenital heart disease (CHD) is approximately 4-10 cases per 1000 newborns. Pediatric patients with CHD are known to be prone to growth retardation and failure to thrive. Acute malnutrition can be identified in $33-51 \%$ of pediatric patients with CHD while chronic malnutrition can be identified in $40-64 \%$ of pediatric patients with CHD. ${ }^{8}$ Hassan et al. ${ }^{9}$ reported higher prevalence of malnutrition in Egypt which was $84 \%$ with $71.4 \%$ of the children experienced severe malnutrition.

The main mechanism of malnutrition in CHD is increased energy expenditure due to cardiac changes which leads to inadequate nutrients. In addition, the hemodynamic status is unstable which affects the children's growth. As the child grows, the cardiovascular system works harder, the basal temperature increases corresponding to increase metabolic rate, and the sympathetic nervous system is activated. Alterations in cardiovascular function manifest as hypoxia and edema which induces malabsorption. Also, the children will suffer from early satiety and anorexia which will reduce dietary intakes. The predictors for malnutrition in CHD include older age at presentation, anemia, pulmonary hypertension, heart failure, decreased oxygen saturation, high metabolic rate, energy disequilibrium, feeding difficulties, and born with high APGAR score. ${ }^{9-11}$

As the CHD causes weight loss, the respiratory and heart muscles are affected as well which further compromises the respiratory and myocardial functions, immunologic responses, and healing capacity. ${ }^{10}$ These children will have longer LOS, repeated hospitalizations, increased diuretic needs, and more likely to be transferred to intensive care unit (ICU). Therefore, malnutrition will significantly increase mortality and morbidity of pediatric patients with CHD. ${ }^{12}$

\section{Disease related malnutrition in children with cancers}

One of the most common conditions associated with malnutrition in pediatric patients is cancer. Fifty percent of pediatric patients with neuroblastoma suffers from malnutrition while only $0-10 \%$ of pediatric patients with leukemia suffers from 
malnutrition. Pediatric patients with medulloblastoma and solid tumors often experience weight loss although criteria for nutritional status do not include weight loss. Furthermore, pediatric patients with solid tumors and leukemia suffers from fat free mass (FFM) loss which can predispose them to infections, frailty, and decreased quality of life. ${ }^{13}$

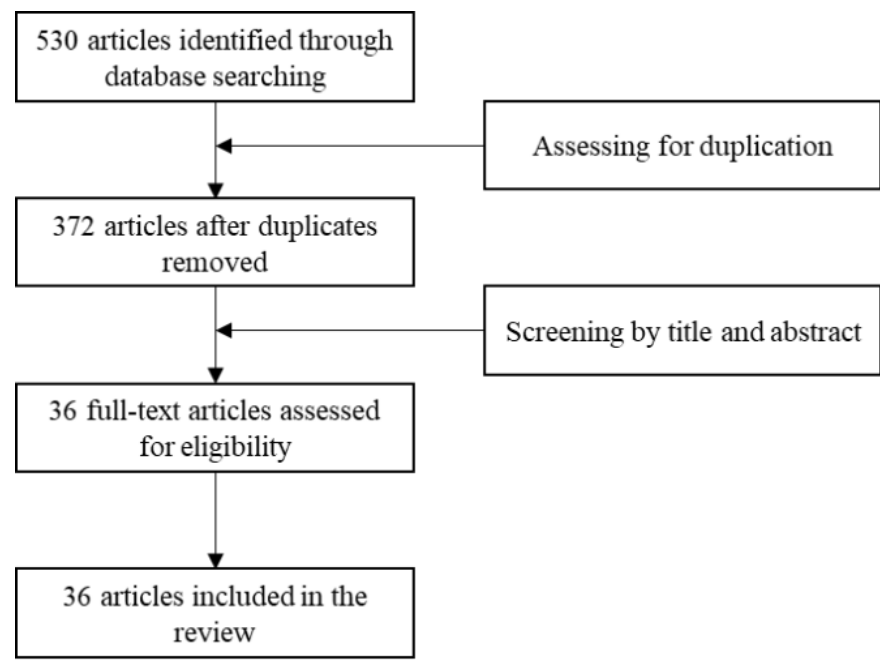

Figure 1. Article selection process

The possible mechanisms of DRM in pediatric patients are less physical activity or altered nutrition utilization, reduced intake, increased metabolic rate or hypermetabolism, as well as loss from vomiting, diarrhea, and malabsorption. In addition, patients who receive corticosteroids might undergo increased catabolism of muscle protein, which leads to reduced FFM. ${ }^{13}$ Zimmermann et al. ${ }^{1}$ found that patients diagnosed at age over 10 years old, having body mass index standard deviation score (BMI SDS) $\leq 1.0$ when diagnosed, and diagnosed with medulloblastoma had strong association with malnutrition during treatment. Several parameters used for defining malnutrition in pediatric patients are body weight, body height, mid upper arm circumference, and skin folds. These parameters are incorporated to determine the $\mathrm{Z}$-scores and then plotted into the reference charts, which are Multicenter Growth Reference Study (MGRS) by World Health Organization (WHO) for children aged 0-2 years old and reference chart by Center for
Disease Control and Prevention (CDC) for children aged over 2 years old. ${ }^{5}$

Pediatric patients with cancer have lower survival rates when they suffer from DRM. Rapid weight loss will increase their risk of febrile neutropenia with bacteremia. ${ }^{14}$ In addition, their quality of life is significantly impaired. While pediatric patients with undernutrition have poor social participation and activities, those with obesity also have psychosocial and cognitive problems. ${ }^{15}$ Difference between disease-related malnutrition in children with congenital heart disease and cancers is shown in Table 1.

\section{Screening for children with disease-related malnutrition}

In order to prevent morbidity and mortality caused by DRM in hospitalized pediatric patients, proper and aggressive treatment should be implemented immediately. ${ }^{12}$ Screening tools for malnutrition should be practical, cost-effective, applicable, and have high reproducibility so it can be performed by physicians, nurses, or dieticians. ${ }^{18}$ To date, there has been no guidelines for screening disease-related malnutrition in pediatric patients. A systematic review by Klanjsek et al. ${ }^{19}$ identified 3 assessment tools and 14 screening tools for malnutrition. The study included 8 screening tools, comprising nutritional risk screening tool in cystic fibrosis $(\mathrm{CF})$, nutritional risk screening tool for pediatric patients with CF, Neonatal Nutrition Screening Tool (NNST), Paediatric Nutrition Screening Tool (PNST), Pediatric Yorkhill Malnutrition Score (PYMS), Nutrition Screening Tool for Childhood Cancer (SCAN), Screening Tool for the Assessment of Malnutrition in Paediatrics; (STAMP), and Screening Tool for Risk on Nutritional Status and

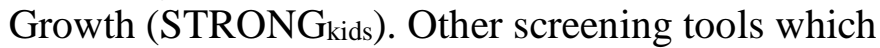
did not have validation study consisted of Nutrition Risk Score (NRS), Pediatric Digital Scaled MAlnutrition Risk Screening Tool (PeDiSMART), St Andrew's Nutrition Screening Instrument (SANSI), Simple Pediatric Nutrition Risk Score (SPNRS), a malnutrition screening tool for children under 2 years old in Zambia, and a screening tool for infants and young children with special health care 
Table 1. Difference between disease-related malnutrition in children with congenital heart disease and cancers ${ }^{13,16,17}$

\begin{tabular}{|c|c|}
\hline $\begin{array}{c}\begin{array}{c}\text { Congenital heart disease-related } \\
\text { malnutrition }\end{array} \\
\end{array}$ & Cancer related malnutrition \\
\hline Mostly born with normal weight & $\begin{array}{l}\text { Involuntary skeletal muscle and adipose } \\
\text { tissue loss }\end{array}$ \\
\hline Pathogenesis & Pathogenesis \\
\hline$\square \quad$ Decreased nutrition intake (+++) & $\square \quad$ Increased nutrition requirement $(+++)$ \\
\hline$\square \quad$ Malabsorption or loss of nutrients (++) & $\square \quad$ Decreased nutrition intake $(++)$ \\
\hline$\square \quad$ Increased nutrition requirement $(+)$ & $\square \quad$ Malabsorption or loss of nutrients (+) \\
\hline$\square \quad$ Impaired utilization $(+/-)$ & $\square \quad$ Impaired utilization $(+/-)$ \\
\hline $\begin{array}{l}\text { Cyanotic children are more common to } \\
\text { suffer from failure to thrive compared to } \\
\text { non-cyanotic children }\end{array}$ & Cause prolonged hospital stay and expenses \\
\hline Feeding intolerance indicated by & Feeding intolerance indicated by \\
\hline$\square \quad$ Abdominal pain & Anorexia \\
\hline$\square$ Abdominal distention & Nausea and vomiting \\
\hline$\square$ Vomiting & \\
\hline Reduced or diminished bowel sound & \\
\hline$\square \quad$ Addition of residual gastric volume & \\
\hline Complication & Complication \\
\hline$\square$ Fluid overload & $\square$ Impaired functional progressively \\
\hline $\begin{array}{l}\square \text { Deteriorating of catabolic response } \\
\text { induced by stress }\end{array}$ & $\begin{array}{l}\square \text { Complications due to treatment } \\
\square \text { Impaired quality of life }\end{array}$ \\
\hline$\square$ Impaired wound healing & \\
\hline $\begin{array}{l}\square \text { Disruption of myocardial and muscle } \\
\text { work }\end{array}$ & \\
\hline $\begin{array}{l}\square \text { Increased incidence of postoperative } \\
\text { complications }\end{array}$ & \\
\hline$\square$ Long-term impaired cognitive function & \\
\hline Poor prognosis & Poor prognosis \\
\hline & $\begin{array}{l}\text { Conservative nutritional management might } \\
\text { partially revert the condition }\end{array}$ \\
\hline Nutritional management & Nutritional management \\
\hline $\begin{array}{l}\text { Tube feeding is preferred due to } \\
\text { inadequate intake }\end{array}$ & $\begin{array}{l}\square \text { Enteral supplementation and tube } \\
\text { feeding can be administered if necessary }\end{array}$ \\
\hline $\begin{array}{l}\square \text { High-energy density formula is preferred } \\
\text { due to fluid restriction and increased }\end{array}$ & $\begin{array}{l}\text { High-energy density formula is preferred } \\
\text { due to increased demand }\end{array}$ \\
\hline $\begin{array}{l}\square \text { Semi- or elemental formula is preferrable } \\
\text { for cyanotic children }\end{array}$ & $\begin{array}{l}\text { Standard formula is preferrable although } \\
\text { semi- or elemental formula might be } \\
\text { necessary in some cases }\end{array}$ \\
\hline
\end{tabular}

needs. Three assessment tools include Clinical Assessment of Nutritional Status (CANS), Subjective Global Assessment (SGA), and Subjective Global Nutritional Assessment (SGNA). ${ }^{19}$

While Klansjek et al. ${ }^{19}$ recommended PYMS along with full nutritional assessment for malnutrition screening in hospitalized pediatric patients, SCAN was developed to screen malnutrition in pediatric patients with cancer. This screening tool includes 5 questions with 1 to 2-point

score. Pediatric patients with cancer who get 3 or more points will be referred to get a full nutritional assessment from a dietician. This tool is proven to be highly sensitive $(100 \%)$ with $39 \%$ specificity, $56 \%$ positive predictive value and $100 \%$ negative predictive value which is ideal for a screening tool. As it is easy to use and valid, SCAN can help to identify malnutrition in pediatric patients early in order to prevent bad outcomes. ${ }^{20}$

Aside from screening tool, there are several key points which indicate high risk for malnutrition should be noted in pediatric patients with cancer. These points consist of age under 2 months old, low socioeconomic status, presence of malnutrition or wasting at diagnosis, history of relapse, getting stem 
cell transplant, receiving emetogenic medications, receiving radiation to gastrointestinal (GI) tract, getting regimens with potential GI complications, getting chemotherapy with GI adverse effects or affecting appetite, and experiencing surgical complications related to GI tract. These patients should be monitored for their body mass index (BMI) and laboratory abnormalities. Measurements for body weight, height, and arm circumference are necessary to estimate BMI, adipose density, and lean body mass. For laboratory examination, prealbumin level can indicate acute malnutrition. ${ }^{21}$ In addition, ratio of C-reactive protein (CRP) level to albumin level can predict acute malnutrition risk. Higher ratio infers to high risk of acute malnutrition. ${ }^{22}$ Other necessary examinations include glucose panel, lipid panel, liver function test, and renal function test to evaluate dietary impact on the patients' body. If the patients are deemed to have a high risk for malnutrition, experiencing weight loss for $5 \%$ or more since the diagnosis, having low BMI for age or arm circumference, being obese or overweight, having difficulty receiving oral nutrient (less than $80 \%$ ), feeding with nasogastric tube, and advised to receive total parenteral nutrition, the patients should be referred immediately to a dietician. ${ }^{21}$

Similarly, there has been no guideline for nutritional screening for pediatric patients with CHD. Traditionally, body weight, height, and arm circumference are used to determine the nutritional status. However, the BMI should be interpreted cautiously in this population because body fat can be overestimated if the patients suffer from edema or have more lean body mass. Pediatric patients with CHD often experience edema due to increase fluid from the cardiac problems; hence, it will mask the wasting or fat loss. Radman et al. ${ }^{23}$ suggested the measurement of triceps skin fold to measure the fat mass more appropriately in pediatric patients with CHD. Another study by Gu et al. ${ }^{24}$ used STRONG ${ }_{k i d s}$ scoring for infants with CHD. This screening tool was proven to have high accuracy $(81.9 \%)$ on predicting malnutrition in infant with CHD. Another screening tool was developed by St. Pierre et al. ${ }^{25}$ This checklist comprised 24 items concerning cardiac diagnosis, chromosomal abnormalities, brain injury, vocal cord paresis, weight, diet, use of feeding tube, GI tolerance, physiological status, vocal cord status, and feeding problems. Although this screening tool is deemed valid and reliable for malnutrition screening in pediatric patients with CHD, there have been no other studies evaluating its use.

STRONG kids $_{\text {was }}$ published in 2010. It was originally tested on children aged 1 month old to 18 years old at 44 hospitals in the Netherlands. The tool screened for subjective findings of fat and muscle loss, reduced nutrient intake, existing high-risk disorders or major surgical plan, loss of body weight or insufficient weight improvement, as well as GI symptoms (nausea, vomiting, diarrhea, and pain). Final score was subtracted and 0 defined as low risk, 1-3 defined as moderate risk, and 4-5 defined as high risk. This screening tool has been proven to be valid, has good reproducibility, and very applicable for screening malnutrition in pediatric patients. ${ }^{18}$

\section{Nutritional management for infants with disease- related malnutrition}

For pediatric patients with CHD, enteral nutrition is advisable because it exerts less complication than parenteral nutrition and better effect on intestines. As it is cheaper than parenteral nutrition, its availability and accessibility are better in developing countries. If the pediatric patients do not experience gastroesophageal reflux or poor tolerance, intragastric feeding is preferrable. Neonates and infants should be instructed to get breast milk as it is free, good for immune system, aids trace elements' absorption, and associated with low risk of necrotizing enterocolitis. Patients with fluid restriction should increase the feeding's energy density about $1 \mathrm{kcal} / \mathrm{ml}$ although osmotic diarrhea can occur. ${ }^{26}$ High-calorie feeding to as high as $125 \%$ of standard feeding are recommended for optimal growth. Another alternative is continuous feeding can be considered if the patients do not respond to high-calorie feeding. ${ }^{27}$ For patients with gastroesophageal reflux, severe weight faltering, or aspiration, gastrostomy or jejunostomy can be an alternative. If the patients were undergone surgery, enteral nutrition should be administered as soon as possible. Use of parenteral nutrition within a week 
after surgery is associated with unfavorable outcomes. ${ }^{26}$ Monitoring of the laboratory markers which represent the patient's nutritional status should be performed. These include CRP, albumin, prealbumin, creatinine, urea, 3-methylhistidine, insulin-like growth factor I, retinol-binding protein, transferrin, and transerythrin. ${ }^{8,27}$

Similarly in pediatric patients with cancer with DRM, enteral nutrition is preferred than parenteral nutrition. Enteral nutrition is associated with good tolerability, improvement of quality of live, better survival rates, and prevent worsening of nutrition status. ${ }^{28}$ Use of enteral tube feeding (ETF) help increasing body weight, relatively easy and safe. In this population, oral supplementation alone can not meet the nutrition requirement. ETF should be used for only 4-6 weeks. If the enteral feeding is necessary for more than 6 weeks, an ostomy will be needed. ${ }^{29}$ Enteral nutrition can be given in bolus, intermittent drip, or continuous administration. Intermittent drip and bolus method is preferred for feeding with gastrostomy because this can simulate normal feeding cycle. On the other hand, continuous feeding is preferred in case of small bowel problems or patients who cannot tolerate other methods. ${ }^{28}$

Formulation for enteral feeding can be classified into standard formula (polymeric), specialized formula, and elemental formula. Standard formula is indicated for patients with intact GI tract. ${ }^{28}$ Nutrientdense formula can also be a choice for enteral feeding. ${ }^{29}$ This formula is indicated for patients who cannot tolerate high volume diet. Elemental formula is indicated for patients with pancreatic disorders and malabsorption. Specialized formula is specially prepared for certain diseases, such as diabetes mellitus, renal disorders, pulmonary disorders, and liver diseases. ${ }^{28}$

Parenteral nutrition is not preferrable because it increases risks of cholestasis, hyperglycemia, hypertriglyceridemia, and infections. It is indicated if the patients cannot tolerate the enteral nutrition or have difficulty absorbing enteral nutrition. ${ }^{29}$ Several contraindications for parenteral nutrition include difficult intravenous access, well-functioned GI tract, and duration of therapy less than 5 days. ${ }^{28}$ Limitations of this parenteral nutrition are high cost and needs of trained professionals. Administration of parenteral nutrition with peripheral access should not be longer than 2 weeks while central access can allow longer duration. ${ }^{29}$ Parenteral nutrition should be started slowly at $15-20$ calories $/ \mathrm{kg}$ body weight/day and limit of 1000 calories per day. The calories should be reduced slowly and parenteral nutrition should be stopped if the patients have achieved more than $60 \%$ of protein and energy needs. ${ }^{28}$ Monitoring of complications should be performed regularly and nutrition status should be re-assessed every two weeks. ${ }^{29}$

One thing should be taken into account when treating children with malnutrition is refeeding syndrome. ${ }^{28}$ This syndrome happened when patients with malnutrition getting aggressive nutrition therapy. Refeeding syndrome occurs due to shifting from catabolism to anabolism, leading to increased insulin secretion and resistance. Hyperinsulinemia and hyperglycemia co-occur along with hypokalemia, hypophosphatemia, hypomagnesemia, and increased fluid volume. Almost all organ systems are affected, such as respiratory, cardiovascular, GI, neurological, musculoskeletal, and hematological systems. This refeeding syndrome can be catastrophic and leads to organ failure, ultimately death. ${ }^{30}$ Patients with DRM for more than two weeks is highly possible to suffer from refeeding syndrome. In order to prevent this, metabolic disorders should be manage properly before initiating parenteral nutrition. ${ }^{28}$ The author develop an algorithm for disease-related malnutrition management in pediatric patient with congenital heart disease and cancers based on several literatures which is shown in Figure 2. ${ }^{26-30}$

\section{Role of nutrient-dense formula for infants with disease-related malnutrition}

Nutrient-dense formula, also known as protein and energy-enriched formula, is a high protein and energy formula formulated for infants to reach the nutrition targets faster and stimulate anabolism. ${ }^{31,32}$ Prior to the development of this formula, clinicians tried to add triglycerides or glucose to the formula or breastmilk or concentrate the formula in order to increase the energy density. However, there were limitations to these methods. First, the infants need 
all nutrients, not only glucose and triglycerides, also the protein-derived energy decreased. Second, this concentrated formula could be too complex for the parents and increased possibility of microorganism contamination. Nutrient-dense formula came as a more cost-effective, highly accessible, and ready touse alternative. ${ }^{33}$

This formula might help infants with DRM because they are prone to fast reduction of nutrition and have very little or no reserve. Nutrient-dense formula are preferrable in pediatric patients with CHD, especially who have fluid restriction, since they have more energy per milk volume. It can decrease $33 \%$ volume intake while providing similar energy intake as standard formula. ${ }^{32}$ Various studies have been conducted to assess the use of nutrient- dense formula in critically-ill pediatric patients. This formula is proven to be associated with good outcomes and well-tolerated in pediatric patients with congenital heart disease following surgery, viral bronchiolitis, and pediatric patients on mechanical ventilator. ${ }^{34}$

Cui et al. ${ }^{32}$ reported that use of nutrient-dense formula in infants with CHD showed good results. The infants tolerated the formula well and they reach the target faster than infants who received standard formula. The intervention group also showed faster anabolism process, proven by positive nitrogen balance and presence of essential amino acids. This positive nitrogen balance points toward anabolism while negative balance points toward catabolism. When an infant undergoes cardiac operation, the inadequate metabolic reserve induces low amino

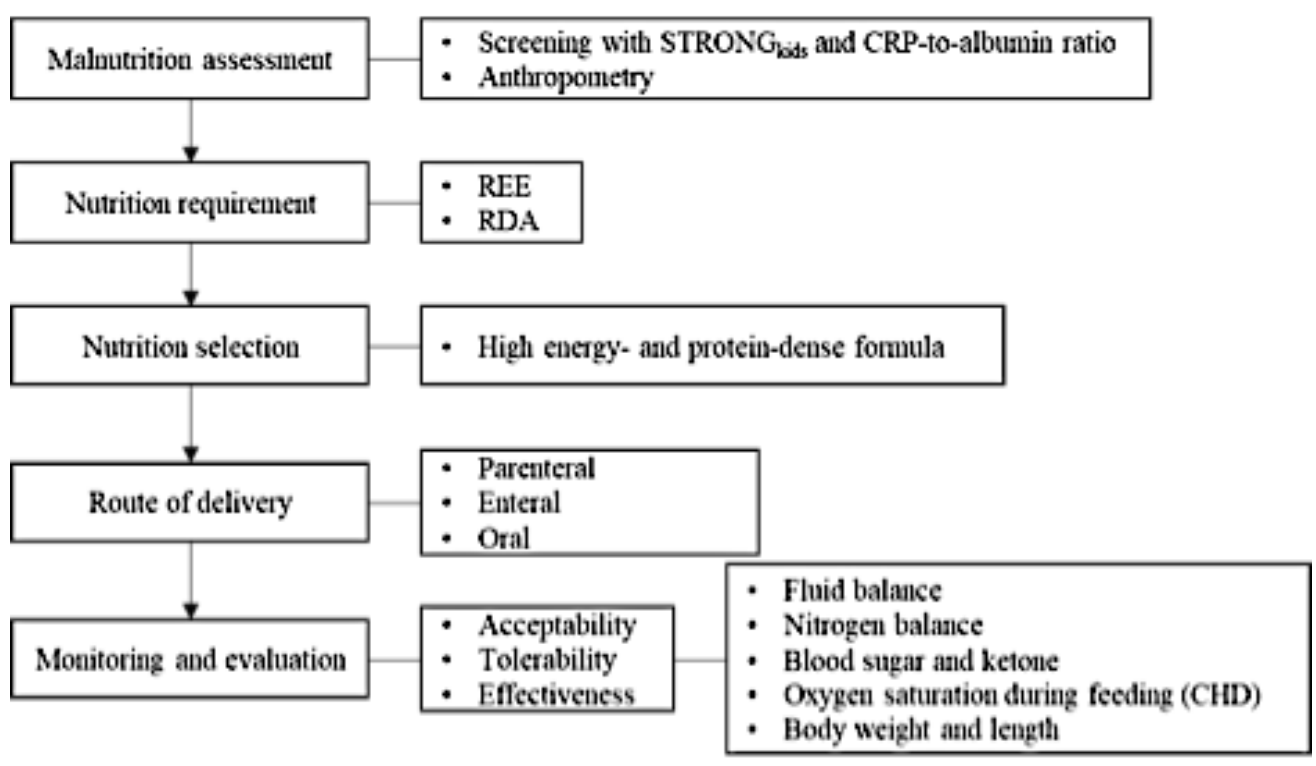

Figure 2. Algorithm for disease-related malnutrition management in pediatric patient with congenital heart disease and cancers ${ }^{26-30}$

CHD: congenital heart disease; CRP: C-reactive protein; RDA: recommended dietary allowance; REE: resting energy expenditure; $\mathrm{STRONG}_{\mathrm{kids}}$ : screening tool for risk on nutritional status and growth 
Table 2. Benefits of using nutrient-dense formula for infants with disease-related malnutrition $^{31-36}$

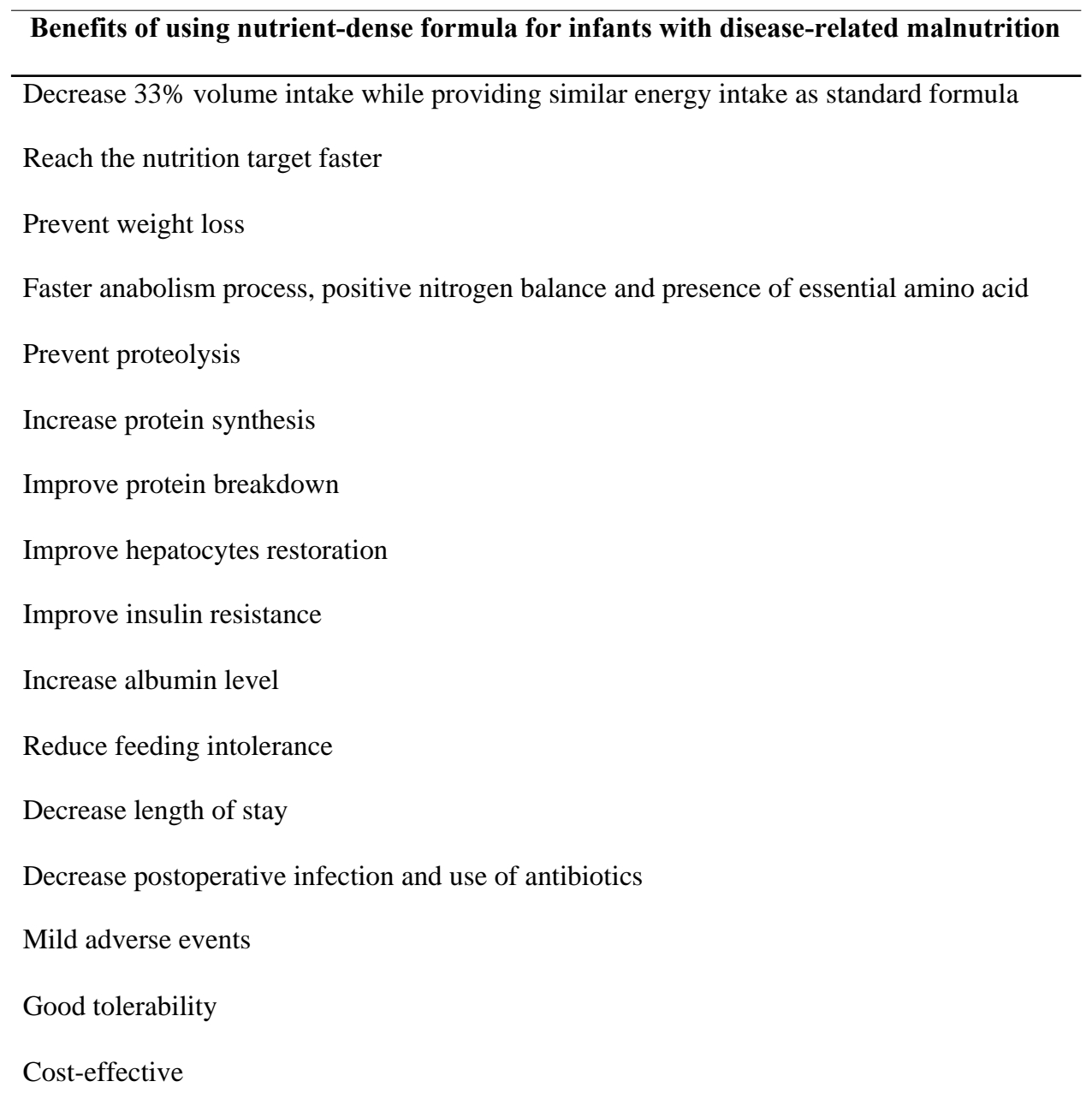

acid levels and substantial proteolysis. Adequate protein and energy intake will prevent this proteolysis which is proven by the administration of nutrient-dense formula in this population. As for the essential amino acids acquired from the formula, they will help increasing protein synthesis as well as improving protein breakdown, hepatocytes restoration, and insulin resistance which leads to improvement of infants' survival and quality of life. $^{32}$

Similarly, Zhang et al. ${ }^{31}$ reported that infants with CHD received more energy and gained weight better with nutrition-dense formula. Also, the patients had increased serum albumin levels which indicated improvement of nutrition status. ${ }^{31}$ Another study by Scheefer et al. ${ }^{35}$ linked the use of nutrient-dense formula with decreased LOS and use of antibiotics during 30 days after CHD surgery. Favorable effects were also shown by reduced use of diuretics and oxygen supplementation. ${ }^{35}$ Favorable outcomes were also reported by Eveleens et al. ${ }^{34}$, who found that critically-ill infants experience weight-for-age (WFA) Z-score following administration of nutrientdense food. These patients achieved the energy target which was determined to be two-fold of the resting energy expenditure. ${ }^{34}$ Benefits of using nutrient-dense formula for infants with diseaserelated malnutrition are shown in Table 2.

Despite no significant different of adverse events in intervention and control group, vomit, diarrhea, and gastric retention were reported in infants getting nutrient-dense formula. ${ }^{32}$ Nutrient-dense formula 
exerts more osmotic pressure, leading to increase risk of GI symptoms, such as gastric retention, diarrhea, nausea, and vomiting. However, these symptoms can be easily managed by medication. The GI system might probably tolerate the formula if given with increasing density. ${ }^{31}$

\section{Conclusion}

To conclude, DRM in pediatric patients with CHD and cancer needs to be identified as soon as possible. Proper screening and management should be performed with multidisciplinary approach to achieve the best outcome. The guidelines for DRM management include assessment of malnutrition, nutrition requirement, nutrition selection, route of delivery, as well as monitoring and evaluation.

\section{Conflict of Interest}

Authors declared no conflict of interest regarding this article.

\section{Open Access}

This article is distributed under the terms of the Creative Commons Attribution 4.0 International Licence

(http://creativecommons.org/licenses/by/4.0/), which permits unrestricted use, distribution, and reproduction in any medium, provided you give appropriate credit to the original author(s) and the source, provide a link to the Creative Commons license, and indicate if changes were made.

\section{References}

1. Zimmermann K, Ammann RA, Kuehni CE, De Geest S, Cignacco E. Malnutrition in pediatric patients with cancer at diagnosis and throughout therapy: A multicenter cohort study. Pediatr Blood Cancer. 2013;60:642-9.

2. Maehara M, Rah JH, Roshita A, Suryantan J, Rachmadewi A, Izwardy D. Patterns and risk factors of double burden of malnutrition among adolescent girls and boys in Indonesia. PLoS One. 2019;14:e0221273.

3. De Silva I, Sumarto S. Child Malnutrition in Indonesia: Can Education, Sanitation and Healthcare Augment the
Role of Income? Journal of International Development. 2018;30:837-64.

4. Rachmi CN, Li M, Alison Baur L. Overweight and obesity in Indonesia: prevalence and risk factors-a literature review. Public Health. 2017;147:20-9.

5. Mehta NM, Corkins MR, Lyman B, Malone A, Goday PS, Carney LN, et al. Defining pediatric malnutrition: a paradigm shift toward etiology-related definitions. JPEN J Parenter Enteral Nutr. 2013;37:460-81.

6. Freijer K, van Puffelen E, Joosten KF, Hulst JM, Koopmanschap MA. The costs of disease related malnutrition in hospitalized children. Clin Nutr ESPEN. 2018;23:228-33.

7. Guenter P, Jensen G, Patel V, Miller S, Mogensen KM, Malone A, et al. Addressing Disease-Related Malnutrition in Hospitalized Patients: A Call for a National Goal. The Joint Commission Journal on Quality and Patient Safety. 2015;41:469-73.

8. Toole BJ, Toole LE, Kyle UG, Cabrera AG, Orellana RA, Coss-Bu JA. Perioperative nutritional support and malnutrition in infants and children with congenital heart disease. Congenit Heart Dis. 2014;9:15-25.

9. Hassan BA, Albanna EA, Morsy SM, Siam AG, Al Shafie MM, Elsaadany HF, et al. Nutritional Status in Children with Un-Operated Congenital Heart Disease: An Egyptian Center Experience. Front Pediatr. 2015;3:53.

10. Monteiro FPM, Araujo TLd, Lopes MVdO, Chaves DBR, Beltrão BA, Costa AGdS. Nutritional status of children with congenital heart disease. Rev Latino-Am Enfermagem. 2012;20:1024-32.

11. Arodiwe I, Chinawa J, Ujunwa F, Adiele D, Ukoha M, Obidike E. Nutritional status of congenital heart disease (CHD) patients: Burden and determinant of malnutrition at university of Nigeria teaching hospital Ituku - Ozalla, Enugu. Pak J Med Sci. 2015;31:1140-5.

12. Hubschman LE. Malnutrition in Congenital Heart Disease. ICAN: Infant, Child, \& Adolescent Nutrition. 2013;5:170-6.

13. Brinksma A, Huizinga G, Sulkers E, Kamps W, Roodbol P, Tissing W. Malnutrition in childhood cancer patients: a review on its prevalence and possible causes. Crit Rev Oncol Hematol. 2012;83:249-75.

14. Loeffen EA, Brinksma A, Miedema KG, de Bock GH, Tissing WJ. Clinical implications of malnutrition in childhood cancer patients--infections and mortality. Support Care Cancer. 2015;23:143-50.

15. Brinksma A, Sanderman R, Roodbol PF, Sulkers E, Burgerhof JG, de Bont ES, et al. Malnutrition is associated with worse health-related quality of life in children with cancer. Support Care Cancer. 2015;23:3043-52.

16. Schiessel DL, Baracos VE. Barriers to cancer nutrition therapy: excess catabolism of muscle and adipose tissues induced by tumour products and chemotherapy. Proceedings of the Nutrition Society. 2018;77:394-402.

17. Martini S, Beghetti I, Annunziata M, Aceti A, Galletti $S$, Ragni L, et al. Enteral Nutrition in Term Infants with Congenital Heart Disease: Knowledge Gaps and Future 
Directions to Improve Clinical Practice. Nutrients. 2021;13.

18. Dos Santos CA, Ribeiro AQ, Rosa COB, de Araujo VE, Franceschini S. Nutritional risk in pediatrics by StrongKids: a systematic review. Eur J Clin Nutr. 2019;73:1441-9.

19. Klanjsek P, Pajnkihar M, Marcun Varda N, Povalej Brzan P. Screening and assessment tools for early detection of malnutrition in hospitalised children: a systematic review of validation studies. BMJ Open. 2019;9:e025444.

20. Murphy AJ, White M, Viani K, Mosby TT. Evaluation of the nutrition screening tool for childhood cancer (SCAN). Clin Nutr. 2016;35:219-24.

21. Joffe L, Ladas EJ. Nutrition during childhood cancer treatment: current understanding and a path for future research. The Lancet Child \& Adolescent Health. 2020;4:465-75.

22. Sidiartha IGL, Wati DK, Subanada IB, Suwarba IGNM. High C-reactive protein/albumin ratio increased risk of acute malnutrition during hospitalization in pediatric patients. International journal of health sciences. 2020;4:32-8.

23. Radman M, Mack R, Barnoya J, Castaneda A, Rosales M, Azakie A, et al. The effect of preoperative nutritional status on postoperative outcomes in children undergoing surgery for congenital heart defects in San Francisco (UCSF) and Guatemala City (UNICAR). J Thorac Cardiovasc Surg. 2014;147:442-50.

24. Gu Y, Hu Y, Zhang H, Fu W, Yang Y, Latour JM. Implementation of an Evidence-Based Guideline of Enteral Nutrition for Infants With Congenital Heart Disease: A Controlled Before-and-After Study. Pediatr Crit Care Med. 2020;21:e369-e77.

25. St Pierre A, Khattra P, Johnson M, Cender L, Manzano $\mathrm{S}$, Holsti L. Content validation of the infant malnutrition and feeding checklist for congenital heart disease: a tool to identify risk of malnutrition and feeding difficulties in infants with congenital heart disease. J Pediatr Nurs. 2010;25:367-74.

26. Argent AC, Balachandran R, Vaidyanathan B, Khan A, Kumar RK. Management of undernutrition and failure to thrive in children with congenital heart disease in low- and middle-income countries. Cardiol Young. 2017;27:S22-S30.

27. Wong JJ, Cheifetz IM, Ong C, Nakao M, Lee JH. Nutrition Support for Children Undergoing Congenital Heart Surgeries: A Narrative Review. World J Pediatr Congenit Heart Surg. 2015;6:443-54.

28. Ackerman D, Laszlo M, Provisor A, Yu A. Nutrition Management for the Head and Neck Cancer Patient. Cancer Treat Res. 2018;174:187-208.

29. Viani K. Parenteral and enteral nutrition for pediatric oncology in low- and middle-income countries. Indian J Cancer. 2015;52:182-4.

30. Obeid OA, Hachem DH, Ayoub JJ. Refeeding and metabolic syndromes: two sides of the same coin. Nutr Diabetes. 2014;4:e120.
31. Zhang H, Gu Y, Mi Y, Jin Y, Fu W, Latour JM. Highenergy nutrition in paediatric cardiac critical care patients: a randomized controlled trial. Nurs Crit Care. 2019;24:97-102

32. Cui Y, Li L, Hu C, Shi H, Li J, Gupta RK, et al. Effects and Tolerance of Protein and Energy-Enriched Formula in Infants Following Congenital Heart Surgery: A Randomized Controlled Trial. JPEN J Parenter Enteral Nutr. 2018;42:196-204.

33. Clarke SE, Evans S, Macdonald A, Davies P, Booth IW. Randomized comparison of a nutrient-dense formula with an energy-supplemented formula for infants with faltering growth. J Hum Nutr Diet. 2007;20:329-39.

34. Eveleens RD, Dungen DK, Verbruggen S, Hulst JM, Joosten KFM. Weight improvement with the use of protein and energy enriched nutritional formula in infants with a prolonged PICU stay. J Hum Nutr Diet. 2019;32:3-10.

35. Scheeffer VA, Ricachinevsky CP, Freitas AT, Salamon F, Rodrigues FFN, Brondani TG, et al. Tolerability and Effects of the Use of Energy-Enriched Infant Formula After Congenital Heart Surgery: A Randomized Controlled Trial. JPEN J Parenter Enteral Nutr. 2020;44:348-54.

36. Marino LV, Meyer R, Cooke ML. Cost comparison between powdered versus energy dense infant formula for undernourished children in a hospital setting. eSPEN Journal. 2013;8:e145-e9. 